\title{
Addressing graduate capability through action research: a cross-disciplinary perspective in a New Zealand context
}

\author{
Qilong Zhang ${ }^{1,2}$ (1)
}

Received: 24 March 2020 / Accepted: 18 August 2020 / Published online: 7 September 2020

(C) The Author(s) 2020

\begin{abstract}
The concept "graduate capability" has been created to respond to the trend that tertiary education graduates routinely encounter uncertainty and complexity. Adopting a multiple-site action research design, this study explored ways to address graduate capability across five disciplines in a New Zealand vocational education institution. Participants were 215 students and 21 teaching staff. Data collection included interviews, team meetings, and a variety of pedagogical documentation. Ethnographic content analysis was used for data analysis which generated five disciplinespecific approaches to graduate capability intervention. Each approach included five dimensions: selection of focus capability items (FCIs) for intervention, composition of FCIs, strategies to address FCIs, impact of the intervention, and relationship between the intervention and the academic programme. This study not only helps the sampled programmes address graduate capability in an intentional and systematic way, but also offers an operational framework for designing capability intervention programmes in similar settings.
\end{abstract}

Keywords Uncertainty · Graduate capability · Action research · Cross-disciplinary

\section{Introduction}

Uncertainty and complexity is a distinct feature of the employment environment facing tertiary education graduates in changing times (Higdon 2016; Molla and Cuthbert 2015). In response to such uncertainty and complexity, the concept of 'capability' has been introduced into tertiary education to categorise non-traditional graduate outcomes which go beyond knowledge and skills. The New Zealand Qualifications Framework provides, "In developing graduate profiles, the qualification developer

Qilong Zhang

qilong.zhang@uaeu.ac.ae

1 Toi Ohomai Institute of Technology, Mokoia Drive, Rotorua 3046, New Zealand

2 United Arab Emirates University, Al Ain, United Arab Emirates 
should consider the full range of capabilities and competencies" (New Zealand Qualification Authority 2016 p. 7). However, it remained an unresolved question how graduate capability can be addressed in tertiary education programmes, and this study was aimed at answering the question.

Understanding the term 'capability' is a starting point for addressing it in a tertiary programme. Classical definitions of capability emphasise the element of 'changing context'. Stephenson and Yorke (1998) defined capability as "an integration of knowledge, skills, personal qualities and understanding used appropriately and effectively-not just in familiar and highly focus specialist contexts, but in response to new and changing circumstances" (p. 2). Stephenson (1998) elaborated, "[Capability] depends much more on our confidence that we can effectively use and develop our skills in complex and changing circumstances than on our mere possession of those skills" (p. 1).

The kernel of the graduate capability conception is the distinction between 'capability' and 'competence', as illuminated by Lester (2014), “[Capability] has a knowit-when-you-see-it property that cannot easily be translated into standards and specifications. Capability has variously been described as about having the potential to become competent, as being similar to competence but less normative or prescriptive" (p. 37). Lester (2014) further clarified, "A high level of capability does not necessarily mean being comprehensively competent, but it does imply being able to know what level of competence is needed and to exercise it wisely" (p. 38).

The above definitions of capability all highlight one's ability to apply knowledge and skills in new, complex, or changing situations which goes beyond knowledge and skills per se. The scope of this study was determined using this conceptualisation of capability.

\section{Discipline-specific capability}

While there exist generic capability items which are common across disciplines (Bowden et al. 2000; McNeil et al. 2012), discipline-specific capability has consistently been the focus of research. With a multinational sample from 11 countries, Harrison and Grant's (2016) research investigated the most desirable graduate capabilities in music higher research degree students. Funded by the Australian Learning and Teaching Council (ALTC), a national project Defining Your Discipline (DYD) was aimed at enabling a discipline to develop a set of graduate capabilities (Dowling and Hadgraft 2014). Australian researchers have reported development of tertiary programmes for embedding graduate capability in journalism at Edith Cowan University (Cullen 2015), biological science at Queensland University of Technology (Firn 2015), chemical engineering at RMIT University (Hadgraft and Muir 2003), and health management at UNSW Australia (Meyer et al. 2007). In NZ, Du Plessis et al.'s (2006) study examined the capabilities that human resource personnel need to possess perceived by HR managers. With students and staff participating from the marketing programmes predominantly from the University of Otago, Gray et al.'s (2007) research explored the capabilities that are 'essential' to the marketing 
profession. With a sample from seven NZ universities, Wells et al.'s (2009) study examined the most important capabilities for the accounting profession. There is a lack of studies internationally, and particularly in NZ, that explore the ways to embed capability from a cross-disciplinary perspective.

\section{Strategies to embed graduate capability}

Given the intervention oriented aim of this study, it was pertinent to examine literature on strategies to 'teach' capability. In a study involving nursing programmes at QUT Australia, Hart et al. (1999) pointed out that the profile of graduate capability development will vary for each student and therefore can only be comprehensively mapped in a collaborative process involving the student. In Kember et al.'s (2007) study involving a university in Hong Kong, specific capability items were selected by panels of academics from each discipline of the university. Meyer et al. (2007) found engaging with key stakeholders to be important for identification of critical capability items. Debuse and Lawley's (2009) analysis of IT advertisements in Australia and the USA identified five key stakeholder groups who determine graduate capability items, including academics, professional bodies, employers, clients, and technology providers.

According to Hart et al. (1999), graduate capability is most readily developed within authentic learning environments. Kember et al. (2007) explored a 'suitable learning environment' for capability development with university undergraduates. Firn (2015) reported some measures taken to incorporate graduate capability, including inquiry-based learning tasks, small group work activities, opportunities for the students to network with the professional community, defence of arguments and decisions, career development training, and deep learning strategies. Some researchers highlighted alignment of assessment tasks with graduate capability development (Nghiem and Bell 2008; O'Sullivan et al. 2012). These strategies informed those in the intervention programmes in our study to a great extent.

\section{The NZ context, the research question, and the conceptual framework}

Regulated within the New Zealand Qualifications Framework, tertiary education in NZ mainly includes universities, institutes of technology and polytechnics, and private training establishments. The New Zealand Qualifications Authority is responsible for quality assurance of all academic programmes except for university programmes which are monitored by the Committee on University Academic Programmes. Given the lack of research in NZ on embedding capabilities into tertiary education and the lack of studies internationally exploring the topic from a crossdisciplinary perspective, there was a need to conduct research with a cross-disciplinary design which could more acutely capture the disciplinary differences. The research question was: How is graduate capability addressed differently in different disciplines in tertiary education in NZ? 
To explore approaches to developing graduate capability, it was important to have a conceptual framework defining what needed to be developed. A review of literature revealed only very few options. The UK researchers Pool and Sewell (2007) developed a conceptual framework known as CareerEDGE which foregrounds five elements of employability: career development learning (Career), experience in work and life (E), degree subject knowledge, understanding and skills (D), generic skills (G), and emotional intelligence (E). The framework was used by Jollands et al. (2015) as a foundation for an Australian national study. While this framework was comprehensive, it was not solely on graduate capability. Dowling and Hadgraft (2013a) conceptualised graduate capability into three strands: technical capability, process capability, and generic capability. Dowling and Hadgraft (2013b) introduced a graduate capability framework which included three components: an overview of the discipline or specialisation; instructions and notes for users; and the set of graduate capability items. In comparison, the Work Ready Plus Graduate Capability Framework (Scott 2016) was ideal for this study.

The Work Ready Plus study was an extensive project involving 3,700 senior university academics, a range of employers, and profession groups in 2014-2016. The Work Ready Plus Graduate Capability Framework "has been validated in studies of successful graduates in nine professions along with studies of educational leaders in schools, VET and Higher Education" (Scott 2016 p. 40). Fullan and Scott (2014) first introduced the concept Work Ready Plus which is characteristic of being sustainability literate, change implementation savvy, inventive, and embracing futureoriented values such as growth, consumption, ICT, and globalisation. Fullan and Scott (2014) tied the notion of Work Ready Plus with "negotiating the messy, fuzzy, dilemma-ridden context of real-world life" (p. 4). The framework comprises five dimensions, with three of the dimensions under the strand of capability (personal capability, interpersonal capability, cognitive capability) and two under competence (role-specific competence, generic competence). The Work Ready Plus Graduate Capability Scale used in this study consists of three factor analysed subscales. The Personal Capability Subscale (14 items) is made up of three interlocked components: self-awareness, decisiveness, and commitment. The Interpersonal Capability Subscale (10 items) is distinguished into two components: influencing and empathising with others. The Cognitive Capability Subscale (14 items) is made up of three components: diagnosis, strategy, and flexibility and responsiveness. The framework enabled our research team to accurately comprehend, interpret, and operationalise gradate capability.

\section{Methodology}

Defined by its aim, the study was intervention focussed. The study was of a participatory action research design where the practitioners were agents of the change and co-researchers (Kemmis and McTaggart 1988; McTaggart 1991). Also, the study was designed as a multisited case study where a problem was investigated in its 
context (Yin 2017) and where multiple cases in multiple disciplines allowed crossdisciplinary comparison (Randell et al. 2011).

\section{The participants}

The project was conducted within an institute of technology in the North Island of New Zealand. Five academic programmes from five disciplines (branches of knowledge) were selected as five action research sites. Except for the Master of Management programme which was a postgraduate programme, all programmes were undergraduate programmes, and except for the Bachelor of Creative Technology programme which was a 3-year programme, all programsme were a 1-year programme. The students were predominantly full-time and would graduate in less than 1 year. Demographics of the students in each programme are omitted for brevity. Staff participants were teachers involved in development and delivery of the capability intervention programmes. Table 1 provides a profile of the five participating programmes including the level and length of the programme, and the numbers of student and staff participants.

The research team included a central research team and five programme research teams. The central research team consisted of three persons: the principal investigator, the project manager, and the career adviser. The central research team met on a weekly basis to liaise with, facilitate, and support the five programme teams. Each programme team consisted of three to five teaching staff and was headed by the programme investigator who was also programme leader or head of department except for the Graduate Diploma in Health Studies programme.

\section{The intervention programmes}

The study followed cyclical stages of "plan, act, observe, and reflect" (McTaggart 1991) and included two cycles. The four stages of each cycle were to develop (plan), deliver (act), and evaluate (observe and reflect) the intervention programme. Each programme was encouraged to exercise ownership-responsible agency in the production of knowledge and the improvement of practice (McTaggart 1991). In particular, it was up to the individual programmes which of the 38 capability items

Table 1 Profile of the participating programmes

\begin{tabular}{llllll}
\hline Programme & Level & Length & \multicolumn{2}{l}{ Student } & Staff \\
\cline { 4 - 6 } & & & Cycle 1 & Cycle 2 \\
\hline NZ certificate in construction trade skills & 3 & 1 year & 27 & 28 & 3 \\
Diploma in early childhood education & 5 & 1 year & 47 & 32 & 5 \\
Graduate diploma in health studies & 7 & 1 year & 25 & 16 & 4 \\
Bachelor of creative technology & 7 & 3 years & 10 & 9 & 4 \\
Master of management & 9 & 1 year & 15 & 6 & 5 \\
\hline
\end{tabular}


would be selected as focus capability items (FCIs) for intervention and how the FCIs would be taught. Due to the evolving, generating nature of the intervention programmes, the details of the intervention programmes were in essence findings rather than methods of the study and therefore are reported in the findings section instead of the methodology section.

Cycle 1 included four stages and was completed during the period January-December 2017. Stage 1 was development of the initial capability intervention programme. All programmes believed that: (1) for feasibility and effectiveness of the capability intervention, a certain number of focus capability items (FCIs) must be selected from a pool of items; (2) Scott's (2016) Graduate Capability Framework is comprehensive enough to be such a pool. Each programme chose FCIs for intervention and strategies to develop the FCIs. Stage 2 was implementation of the initial capability intervention programme. Each programme delivered the initial capability intervention programme and kept related pedagogical documentation. Stage 3 was collection of data. Stage 4 was analysis of data. Aimed at improving the intervention programme, Cycle 2 repeated the four stages and was completed during the period January-December 2018.

\section{Data collection}

Data collection included interviews, staff meetings, and pedagogical documentation. Individual and focus group semi-structured student interviews took place in a classroom or interview room of the department. The overarching interview questions were as follows: (1) How did your teachers help you to develop these capability items? (2) How much did you learn about these capability items as a result? (3) What else do you think the teachers can do to help you develop these capability items in the future? Teacher interviews took place in a staff office or interview room of the department. The overarching interview questions were: (1) How did you help the students to develop the capability items? (2) How much do you think your students had learned about these capability items as a result? (3) What else do you think you can do to help the students develop these capability items in the future? All interviews were audio recorded and transcribed. Monthly hour-long meetings were held with the programme teams to discuss matters relating to the action research project exclusively. Pedagogical documentation included video recordings, photos, staff reflection notes, student work sample, and reflective folder.

\section{Data analysis}

Ethnographic content analysis (ECA) (Altheide 1987, 2008) was used to identify patterns within the intervention practices. ECA assumes that the meaning of a message is reflected in various modes of information exchange, the context and other nuances, which require the researcher to move reflexively between concept developing, sampling, data collection, data coding, and interpretation (Altheide 1987). ECA is "an integrated method, procedure, and technique for locating, identifying, retrieving, and analysing documents for their relevance, significance, and meaning. The 
emphasis is on discovery and description of contexts, underlying meanings, patterns, and processes" (Altheide 2008 p. 287). 'Documents' in this study included interview transcripts, meeting minutes, and sundry forms of pedagogical documentation.

\section{Findings}

Five dimensions of the capability intervention programme were revealed to reflect disciplinary differences: method of selecting FCIs, composition of FCIs, strategies to develop the FCIs, impact of intervention, and relation of the intervention with the academic programme.

\section{Method of selecting FCls}

For the Construction Trade program, believing that the interpersonal and cognitive capability was too hard for their students, the programme team selected FCIs which all belonged to the construct of personal capability. For the Early Childhood programme, at the local advisory committee (LAC) meeting, each member of the LAC was invited to select their top five items, then at the teaching team meeting, the LAC version of FCIs was reviewed and revised. For the Health Studies programme, FCIs were selected by the programme team according to the graduate profile. For the Creative Technology programme, aligned with the graduate profile outcomes, initial FCIs were selected by the programme according to 'design/creative process' and 'designer's way of knowing'. For the Management programme, quantitative survey was used to allow the students and staff to select the 'the most important' items.

\section{Composition of FCls}

Table 2 shows all the FCIs selected by all programmes in Cycle 2, which were revised from those in Cycle 1. As Table 2 shows, for the Construction Trade programme, all FCIs were items of personal capability. For both the Early Childhood programme and the Health Study programme, there were three items of personal capability, three items of interpersonal capability, and two items of cognitive capability. For the Creative Technology programme, there were two items of personal capability, three items of interpersonal capability, and three items of cognitive capability. The Management programme selected five items of personal capability, two items of interpersonal capability, and one item of cognitive capability. To the Construction Trade programme, personal capability items were 'easier' than interpersonal and cognitive capability and therefore were dealt with first and foremost. Personal capability items were also prioritised by the Early Childhood (3), Health Study (3) and Management (5) programmes. The Creative Technology programme chose the most cognitive capability items (3). The most frequently chosen capability items were: 1.5 (maintaining work/life balance) and 
Table 2 Focus capability items (FCIs) of five programmes

CT EC HS C $\mathrm{M}$

Personal capability

1.2. Understanding my personal strengths and limitations

1.3. Being willing to face and learn from my errors

1.4. Bouncing back from adversity

1.5. Maintaining a good work/life balance and keeping things in

1.6. Remaining calm under pressure or when things take an

1.10. Having energy, passion and enthusiasm for my profession

1.11. Wanting to produce as good a job as possible

1.12. Being willing to take responsibility for projects and how they turn out

1.13. Willingness to persevere when things are not working out as anticipated

Interpersonal capability

2.4. Motivating others to achieve positive outcomes

2.7. Giving and receiving constructive feedback to/from work colleagues and others

2.8. Empathising and working productively with people from a wide range of backgrounds

2.9. Listening to different points of view before coming to a decision

2.10 Being able to develop and contribute positively to team-based programmes

Cognitive capability

3.4. Being able to identify the core issue from a mass of detail in any

3.5. Seeing and then acting on an opportunity for a new direction

3.8. Thinking creatively and laterally

3.11. Setting and justifying priorities for my daily work

3.13. Making sense of and learning from experience

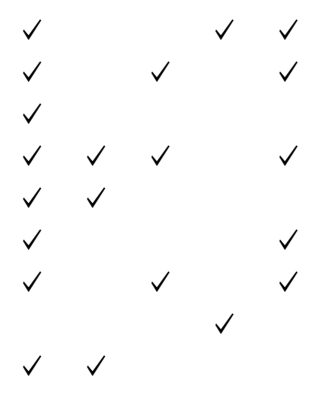

$C T \mathrm{NZ}$ certificate in construction trade skills, 1 year, $E C$ diploma in early childhood education, 1 year, $H S$ graduate diploma in health studies, 1 year, $C$ bachelor of creative technology, 3 years, $M$ master of management, 1 year

2.10 (contributing to team-based programmes), which were chosen by all programmes except the Creative Technology programme and the Construction Trade programme, respectively. The least chosen capability items were 1.4 (bouncing back from adversity), 1.12 (taking responsibility), 2.4 (motivating others), 2.8 (empathising), and 3.4 (identifying the core issue) each of which was chosen by only one programme. No item was chosen by all programmes. Overall, there was an apparent disparity and divergence in FCIs between programmes.

\section{Strategies to develop FCls}

For the Construction Trade programme, strategies to develop FCIs were formalised and labelled by the mnemonic 6Rs-reword, recognise, remember, reinforce, remind, and 
respond. The programme investigator perceived the trade students to have difficulty in understanding the capability items which were expressed in "big words", and therefore, chose to reword the items using "simple words". The teaching staff helped the students to recognise the importance of the FCIs, remember the content of the FCIs, and reinforce the capability items by talking to the students about the individual FCIs in daily conversations. Also, the teaching staff reminded the students of the FCIs (e.g. the posters were made in triplicate for the lecturers to hold up and show the students at any time), and responded to and commended the students when they enacted an FCI (e.g. the lecturer took photos of relevant activities and showed the photos to the students).

For the Early Childhood programme, the strategies were formalised and labelled by the mnemonic Cedar-LED_contextualise, explain, define, assess, reflect, label, exemplify, and document. The teaching staff contextualised the FCIs as dispositions in the early childhood context, explained to the students what a disposition was. The students defined a disposition in their own language, assessed their level of the disposition, reflected on their strategies to strengthen each disposition in him/herself. The students were encouraged to label (name or denominate) the disposition when it was displayed, wrote a learning story to exemplify how they displayed a certain disposition, and documented any moments when they displayed a certain disposition.

For the Health Studies programme, strategies were formalised and labelled by the mnemonic MOVES - mix, orientation, volunteer, employer, simulation. Regular and deliberate mixing of peer groups was practised in teaching. During the orientation week, workshops were facilitated with a focus on the FCIs. The students were supported to gain practice experience through volunteering work that reflected the expectations of the industry. Current employers were invited as guest speakers to talk to the students about the FCIs. Scenarios, case-based simulation of work, were implemented to help the students develop the FCIs.

For the Creative Technology programme, strategies were formalised and labelled by the mnemonic WOW-PLACE_-workshop, outcome, work, plan, lecture, assessment, critique, exhibition. The teaching staff ran workshops on certain topics such as starting a business operating within the creative sector. Learning outcomes for the courses required students to address FCIs. The students were encouraged to work on individual art and design work. The fortnightly action plans detailed what the students needed to do, artist statements and their overarching creative projects. In the lectures, the terminology around capability was described to the students. Students were required to hand in their project-based assessments by the due date. The fortnightly critiques were in a class/group situation or one on one. The end of semester/year art and design exhibition was a collaborative experience.

For the Management programme, strategies were formalised and labelled by the mnemonic GRAMMAR - group activities, relationship, advice, mentoring, marking, assessment, resit policy. Group activities were arranged to develop FCIs. A positive relationship between the teaching staff and the students was the pre-requisite for capability intervention. The students were encouraged to seek advice from the career adviser. Mentoring was provided throughout the course. The teaching utilised marking of assessment, design of assessment, and resit policy to develop certain FCIs. 


\section{Impact of intervention}

Based on interviews with both students and staff, it was ascertained that the intervention programme had a positive effect on the students. For the Construction Trade students, many were taught for the first time the capability items such as 'learning from errors' and 'remaining calm under pressure'. The Early Childhood Education students enjoyed the classroom activities purposely designed for developing dispositions, completed several types of written work, and were supported to understand the theoretical underpinning of what they were expected to do. The Creative Technology staff made explicit the link between the FCIs and the graduate profiles, which led to students becoming more cognisant of the importance of the FCIs. Having ample opportunities to experience what future jobs looked like, the Health Studies students understood well in what ways they should be prepared for those jobs. The Management students reported that they had many opportunities to have dialogues about a range of employability issues with the tutors, and had cleared up all doubts.

In addition to the students' exposure to the FCIs as described above, a remarkable impact of the intervention programme was the students' deepened critical reflection on issues related to the FCIs, which was important for graduate capability development. For example, in the interviews, the students actively expressed their views on teachability of the FCIs. Some students believed that capability had to be learnerdetermined, as Student E05 explained,

It is something you need to learn on your own because no one can actually teach you how to prioritise these, it is your own life, they can give us input, but they can't say you must do this way, not something we are going to get told to do, there does not need to be an assignment on that.

Some students emphasised the teaching approach, as Student E04 articulated,

I do think it is teachable, but not by a tutor in the front trying to teach us, that's not going to work, and I don't know how they could. I think it is teachable by having the whole support from your class, your teachers and classmates, everyone's support.

Some students held that it was too late to teach capability in tertiary education, as Student CT02 enunciated, "No, not when you come to this level, not in tertiary level of study, I don't think, too late, these have to be developed probably in primary [laugh]." The students showed some enlightening thoughts on learning and teaching individual FCIs. Student C04 recounted,

Being willing to learn from my errors is very important for us in this carpentry course, since we make a lot of errors doing carpentry work, e.g. putting a nail in a wrong spot, or cutting the timber in a wrong way, not wearing safety gear, we learn quite quickly not to make same mistakes. 


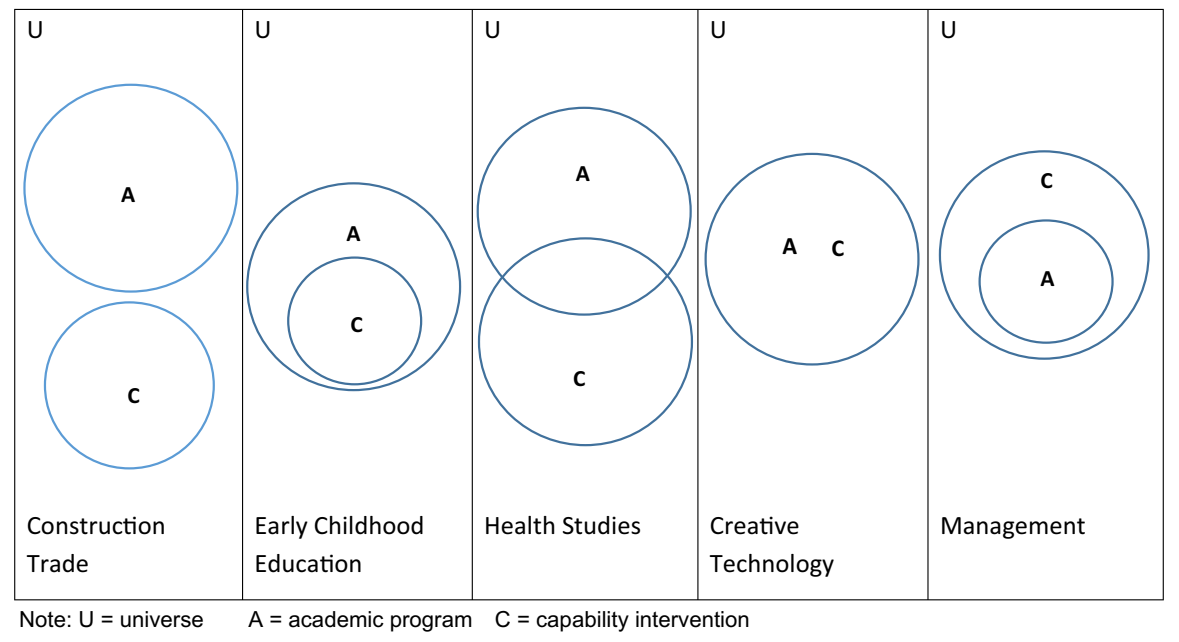

Fig. 1 Relation between each intervention programme and its academic programme. $U$ universe, $A$ academic programme, $C$ capability intervention

\section{Relation of the intervention with the academic programme}

The relation of the capability intervention with the academic programme in each of the five disciplines can be delineated utilising the concepts of "set" and "subset" in mathematics and illustrated with Venn diagrams (Fig. 1). In each diagram, $\mathrm{U}=$ universe (sum experience of a student), $\mathrm{A}=$ academic programme, $\mathrm{C}=$ capability intervention programme.

For the Construction and Trade programme, capability intervention (C) was additional, separate from the academic programme (A). Although the capability intervention had an impact on students, staff, and teaching practice, the academic programme remained intact. Similarly, the capability intervention was not dependent on the academic programme. For the Early Childhood programme, capability intervention was naturally absorbed by the academic programme. It was newly added, and became a natural and complementary part of the academic programme. Specifically, the dispositionoriented C was part of A which also foregrounded disposition. For the Health Studies programme, $\mathrm{C}$ was added, and maintained its own structure as a planned employability initiative. $\mathrm{A}$ and $\mathrm{C}$ intersected in certain areas and enhanced each other. The two programmes were collaborative and mutually complementary, for example, work experience was created for dual purposes (i.e. bridging the gap between theory and practice for A; and addressing FCIs for C). For the Creative Technology programme, A and C overlapped and were congruent. They were the same entity in essentially all senses. It was documentation and description by the research team that created a conceptually separate capability intervention programme. For the Management programme, 
capability intervention was conceptually larger than the academic programme. This is because the academic programme was considered only one avenue of developing graduate employability. Also, changes were made to A because of $\mathrm{C}$, not the other way around. $\mathrm{C}$ permeated in both academic and non-academic areas including teaching, assessment, and pastoral care.

\section{Discussion}

The action research project revealed five dimensions of difference in approach to developing graduate capability across five disciplines. The differences reflect some of the distinctive features of five disciplines. Several issues are worth discussing and reflecting on.

\section{Focus capability items and how they should be determined}

By coining the term 'focus capability item' and itemising graduate capability, this study endorsed the reductionist approach (Verschuren 2001) to conceptualising 'capability'. Also, the word 'focus' recognised the importance of prioritisation in determining the content of an intervention programme. In this study, perceived by each programme, focus capability items were not only 'the most important' but also the most likely to be changed through intervention in a tertiary education setting.

The composition of focus capability items was different across five disciplines, with not a single item selected by all five disciplines and only two items selected by four of the five disciplines. At least two factors had caused the differences. First, each discipline or industry had different requirements of qualified employees. For example, for people who are in a managerial or teaching role, greater weight is placed on 'motivating others to achieve positive outcomes' (Item 2.4) while the same capability item may not be equally important to a computer software writer. While there certainly are universally important capability items in changing and uncertain times, for students in the five different disciplines, 'the most important' capability items were different. Second, the job market is influential. Degree of difficulty in finding employment is different in different industries (Judd et al. 2015), which may affect how the educators prioritise graduate capability items. For example, capability items that were essential to successfully starting a business were prioritised in the Creative Technology discipline.

The five programme teaching teams played a key role in determining focus capability items. Literature has shown the importance of consultation with key stakeholders for determining capability items, including employers, professional bodies, and students (Kember et al. 2007; Meyer et al. 2007). However, stakeholder consultations did not take place in this action research as it did in previous studies. In particular, in this study, except for the Master of Management students who were consulted through a questionnaire survey, no student perspective was sought on which capability items should be selected for intervention. There are reasons for the lack 
of consultations. This study was undertaken in a NZ institute of technology which was vocational education oriented and the five programmes were largely vocational. Predominantly, the teaching staff had a strong industry background and maintained a close relationship with employers. The teaching staff had up-to-date information on what capability the employers expected the students to possess. Also, the teaching staff had firsthand knowledge of what capability the students were currently lacking. Therefore, the teaching staff were somewhat proxy of several stakeholders, and were well informed in terms of making the decision on what capability items were to be prioritised for intervention. The five programme teaching teams were confident that they were in the best position to make the choice on focus capability items. A typical example was from the Early Childhood Education team. When making the decision, the team consulted their local advisory committee (LAC); however, they did not fully adopt the LAC version of focus capability items.

\section{Uniqueness of the strategies of each discipline}

While certain strategies were used by more than one programme or even all programmes, strategies used by each programme were uniquely linked to the characteristics of the discipline. The strategies of the Construction Trade programme were congruent with how the trade skills were taught. The FCIs were understood by the teaching team as trade skills, and the strategies were very much like those used for teaching the students to master trade skills. Disposition is the backdrop of all strategies used by the Early Childhood programme since learning disposition is a central concept underpinning all learning in NZ early childhood education (Ministry of Education 2017). Capability was rephrased as disposition in the discipline, and the intervention was focussed on explaining, defining, assessing, labelling and exemplifying dispositions. The teaching staff likened acquisition of dispositions among teacher candidates to that among young children. Simulation was the soul of the Health Studies programme. There was no professional experience component in the 1-year health programme, and therefore, the team placed great weight on simulation. The strategies of the Creative Technology programme naturally replicated the authentic "design cycle" which was the core concept of the discipline. Strategies of work, plan, critique, exhibition were all essential components of creative art and design. The management programme did not have a specific and definite career path and employment environment, and the intervention was significantly extended to pastoral care (relationship, mentoring), assessment, and the wider teaching areas.

Overall, strategies used in each of the five programmes were discipline determined. This echoes the finding in previous studies that graduate capability is best developed within an authentic learning environment (Hart et al. 1999) and suitable learning environment (Kember et al. 2007). Also, most of the strategies reported in previous studies were also used in one or more of the five disciplines in this study, including inquiry-based learning tasks, group activities, defence of arguments, deep learning strategies (Firn 2015) and alignment of assessment tasks with graduate capability development (Nghiem and Bell 2008; O'Sullivan et al. 2012). 


\section{Calibration of graduate capability intervention}

At the outset of the study, the idea of focussing on some capability items was embraced by all programme teams, and it was unanimously agreed that the 38 items of the Work Ready Plus Graduate Capability Framework (Scott 2016) were too many for intervention. Hence the question: How many are 'too many'? To answer the question, three aspects need to be considered. First, to what extent graduate capability intervention has been included in the programme graduate profiles and the learning outcomes of individual courses. This will to a large extent determine what extra should be done about graduate capability at the programme level. Second, how early the institution starts addressing graduate capability. In her research, Bridgstock (2009) concluded that the embedded graduate employability initiative should start from the first year, and continue until the final year, of the tertiary education. In our action research, most programmes were a 1-year programme and therefore might need more intense intervention. Third, how the intervention programme sits with the academic programme. In our study, five types of relationship were identified between the capability intervention programme and the academic programme. Depending on the different types of such relationship, the magnitude of the capability intervention will vary. For example, in the Creative Technology discipline, the capability intervention programme and the academic programme were identical, and apparently the magnitude of capability intervention as such was smaller compared to other disciplines.

In practice, calibration of capability intervention programmes in individual tertiary institutions may also be affected by the leaders' own understanding of, and belief about, graduate capability. For example, Stephenson (1998) warned against the practice of 'separate development of capability' that is often referred to as 'bolt-on capability'. Also, Bridgstock (2009) raised a question on the "balance between orthodox pedagogy and the broadened employability agenda" (p. 39). It is certain that there is not a so-called optimal scale or magnitude of the capability intervention programmes that applies to all tertiary institutions; rather, it is context bound and can only be determined after the local contexts are considered.

\section{Contributions of the study}

The study made several contributions. The findings from the study including the disciplinary differences in FCIs, strategies, and intervention calibration are enlightening to practitioners and researchers who are in the position to engage in similar teaching and research initiatives. Specifically, the study shows that the Work Ready Plus Graduate Capability Framework can be used for multiple disciplines but will require discipline-specific adjustments. Also, the study informs that graduate capability intervention requires a discipline-based, teaching staff led approach rather than a 'one-size-fits-all', top-down approach. The study illustrates the crucial influence of the diverse teaching and learning contexts on graduate capability intervention and therefore highlights that teaching staff, as agents of the change, play a vital role in graduate capability intervention. In addition, the study is among the few, if any, action research projects that compare the approach to developing graduate capability across several disciplines. 


\section{Limitations to the study and future direction}

There are limitations to the study. First, due to its focus, the study was unable to provide in-depth analysis of certain aspects of certain findings, for example, to what extent each of the evolved five intervention programmes was ideal; to what extent the 'proxy stakeholders' approach adopted by four of the five programmes was tenable. Second, there lacked systematic evaluation of the effect of the intervention programmes, in particular, the long--term effect was unknown. Third, due to availability, not all five participating programmes were at the same level.

In spite of the limitations, considering its action research design, we are confident in its validity and reliability. The action research journey enabled us to give much thought to a number of issues related to graduate capability which are worth exploring in the future. It is necessary to further investigate to what extent the students have actually benefited from capability intervention across disciplines. Longitudinal research can be designed to examine learners' enhanced self-efficacy in future career success, learners' progress in capability development perceived by their educators, and graduates' enhanced capability perceived by their employers. More data collection and analysis methods can be used to gauge the pattern of change, for example, ongoing evaluative and reflective feedback from all internal and external stakeholders.

\section{Concluding remarks}

The aim of the study was to explore the different ways to address graduate capability in different disciplinary contexts in tertiary education. Utilising a participatory action research design, the multisited case study foregrounded its context of multiple disciplines and enabled cross-disciplinary comparison. The findings from the study reaffirm our proposition that authentic graduate capability intervention should ideally be designed in the teaching and learning context and executed by the teaching staff. Due to the importance of the context, the five disciplinary approaches generated in this study are by no means formulaic but generative. The study does not offer any recipe for effective capability intervention but to exemplify a cross-disciplinary approach for addressing graduate capability.

Acknowledgements This article reports a research project funded by Ako Aotearoa (RFP17-206). Project team: Qilong Zhang (principal investigator), Heather Hamerton, David Gough, Jon Sadler, Tina Mischewski, Megan Ruha, Aliyu Abdullahtef, Joanne Hayes, Debra Laraman, John Kelly, Joanne Donovan, Rawhia Te Hau-Grant, Malcolm Frost, Ruth Barnes, Tepora Emery, Roberta Skeoch, Karoline Setu-Galo.

Open Access This article is licensed under a Creative Commons Attribution 4.0 International License, which permits use, sharing, adaptation, distribution and reproduction in any medium or format, as long as you give appropriate credit to the original author(s) and the source, provide a link to the Creative Commons licence, and indicate if changes were made. The images or other third party material in this article are included in the article's Creative Commons licence, unless indicated otherwise in a credit line to the material. If material is not included in the article's Creative Commons licence and your intended use is not permitted by statutory regulation or exceeds the permitted use, you will need to obtain permission 
directly from the copyright holder. To view a copy of this licence, visit http://creativecommons.org/licen ses/by/4.0\%.

\section{References}

Altheide, D. L. (1987). Reflections: Ethnographic content analysis. Qualitative Sociology, 10(1), 65-77.

Altheide, D. L. (2008). Ethnographic content analysis. In L. M. Given (Ed.), The SAGE encyclopedia of qualitative research methods (pp. 287-288). Thousand Oaks: SAGE Publications.

Bowden, J., Hart, G., King, B., Trigwell, K., \& Watts, O. (2000). Generic capabilities of ATN university graduates. Canberra: Australian Government Department of Education, Training and Youth Affairs.

Bridgstock, R. (2009). The graduate attributes we've overlooked: Enhancing graduate employability through career management skills. Higher Education Research \& Development, 28(1), 31-44.

Cullen, T. (2015). A capstone unit for tertiary journalism programmes that aims to facilitate the demonstration of graduate capabilities. Asia Pacific Media Educator, 25(2), 297-304.

Debuse, J., \& Lawley, M. (2009). Desirable ICT graduate attributes: Theory vs. practice. Journal of Information Systems Education, 20(3), 313-324.

Dowling, D., \& Hadgraft, R. (2013a). The DYD stakeholder consultation process: A user guide. Sydney: Office of Learning and Teaching, Department of Industry. Innovation, Science, Research and Tertiary Education.

Dowling, D., \& Hadgraft, R. G. (2013b). A Graduate capability framework for environmental engineering degree programs: A guide for Australian universities. Sydney: Office of Learning and Teaching, Department of Industry. Innovation, Science, Research and Tertiary Education.

Dowling, D., \& Hadgraft, R. G. (2014). Define Your Discipline (DYD): Final Report of the DYD project: Defining your discipline to facilitate curriculum renewal in undergraduate programs. Sydney: Office for Learning and Teaching, Department of Education.

Du Plessis, A. J., Beaver, B., \& Nel, P. S. (2006). Closing the gap between current capabilities and future requirements in human resource management in New Zealand: Some empirical evidence. Journal of Global Business and Technology, 2(1), 33-47.

Firn, J. (2015). 'Capping off' the development of graduate capabilities in the final semester unit for biological science students: Review and recommendations. Journal of University Teaching and Learning Practice, 12(3), 3.

Fullan, M., \& Scott, G. (2014). New pedagogies for deep learning whitepaper: Education PLUS. Seattle: Collaborative Impact SPC.

Gray, B. J., Ottesen, G. G., Bell, J., Chapman, C., \& Whiten, J. (2007). What are the essential capabilities of marketers? Marketing Intelligence \& Planning, 25(3), 271-295.

Hadgraft, R., \& Muir, P. (2003). Defining graduate capabilities for chemical engineers at RMIT. In Engineering education for a sustainable future: Proceedings of the 14th annual conference for australasian association for engineering education and 9th Australasian Women in Engineering Forum ( $p$. 91). Australasian Association for Engineering Education.

Harrison, S., \& Grant, C. (2016). Chasing a moving target: Perceptions of work readiness and graduate capabilities in music higher research degree students. British Journal of Music Education, 33(2), 205-218.

Hart, G., Bowden, J., \& Watters, J. (1999). Graduate capabilities: A framework for assessing course quality. Higher Education in Europe, 24(2), 301-308.

Higdon, R. D. (2016). Employability: The missing voice: How student and graduate views could be used to develop future higher education policy and inform curricula. Power and Education, 8(2), $176-195$.

Jollands, M., Clarke, B., Grando, D., Hamilton, M., Smith, J., Xenos, S., et al. (2015). Developing graduate employability through partnerships with industry and professional associations. Sydney: Office for Learning and Teaching, Department of Education and Training.

Judd, M.-M., Knight, C., Lovell, C., Kinash, S., Crane, L. H., McLean, M., et al. (2015). Case studies to enhance graduate employability: Generalist disciplines. Sydney: Australian Government Office for Learning and Teaching. 
Kember, D., Leung, D. Y., \& Ma, R. S. (2007). Characterizing learning environments capable of nurturing generic capabilities in higher education. Research in Higher Education, 48(5), 609-632.

Kemmis, S., \& McTaggart, R. (1988). The action research planner. Melbourne: Deakin University Press.

Lester, S. (2014). Professional standards, competence and capability. Higher Education, Skills and Workbased Learning, 4(1), 31-43.

McNeil, H. P., Scicluna, H. A., Boyle, P., Grimm, M. C., Gibson, K. A., \& Jones, P. D. (2012). Successful development of generic capabilities in an undergraduate medical education program. Higher Education Research \& Development, 31(4), 525-539.

McTaggart, R. (1991). Principles for participatory action research. Adult Education Quarterly, 41(3), $168-187$.

Meyer, L. D., Hodgkinson, A. R., Knight, R., Ho, M. T., di Corpo, S. K., \& Bhalla, S. (2007). Graduate capabilities for health service managers: Reconfiguring health management education@ UNSW. Australian Health Review, 31(3), 379-384.

Ministry of Education, \& Ministry of Education. (2017). Te Whāriki: He Whāriki Mātauranga Mō Ngā Mokopuna O Aotearoa: Early Childhood Curriculum. Wellington: Ministry of Education

Molla, T., \& Cuthbert, D. (2015). The issue of research graduate employability in Australia: An analysis of the policy framing (1999-2013). The Australian Educational Researcher, 42(2), 237-256.

New Zealand Qualification Authority. (2016). Zealand qualifications framework. Retrieved August 27, 2020, from https://www.nzqa.govt.nz/assets/Studying-in-NZ/New-Zealand-Qualification-Frame work/requirements-nzqf.pdf.

Nghiem, L., \& Bell, M. E. (2008). Calibrating engineering graduate capabilities against assessment tasks: A preliminary study. In The Australasian Association for Engineering Education (AAEE) 19th Annual Conference, (pp. 1-6). Rockhampton, Qld, Australia: CQUniversity Australia.

O’Sullivan, A. J., Harris, P., Hughes, C. S., Toohey, S. M., Balasooriya, C., Velan, G., et al. (2012). Linking assessment to undergraduate student capabilities through portfolio examination. Assessment \& Evaluation in Higher Education, 37(3), 379-391.

Pool, L. D., \& Sewell, P. (2007). The key to employability: Developing a practical model of graduate employability. Education and Training, 49(4), 277-289.

Randell, R., Wilson, S., \& Woodward, P. (2011). Variations and commonalities in processes of collaboration: The need for multi-site workplace studies. Computer Supported Cooperative Work, 20(1-2), 37-59.

Scott, G. (2016). Transforming graduate capabilities and achievement standards for a sustainable future: Key insights from a 2014-2015 National Senior Teaching Fellowship. Sydney: Australian Government Office for Learning and Teaching.

Stephenson, J. (1998). The concept of capability and its importance in higher education. In J. Stephenson \& M. Yorke (Eds.), Capability and quality in higher education (pp. 1-13). London: Kogan Page.

Stephenson, J., \& Yorke, M. (1998). Capability and quality in higher education. London: Kogan Page.

Verschuren, P. J. (2001). Holism versus reductionism in modern social science research. Quality and Quantity, 35(4), 389-405.

Wells, P., Gerbic, P., Kranenburg, I., \& Bygrave, J. (2009). Professional skills and capabilities of accounting graduates: The New Zealand expectation gap? Accounting Education: An International Journal, 18(4-5), 403-420.

Yin, R. K. (2017). Case study research and applications: Design and methods. Thousand Oaks, CA: Sage.

Publisher's Note Springer Nature remains neutral with regard to jurisdictional claims in published maps and institutional affiliations.

Qilong Zhang works as a Senior Lecturer in Education at Toi Ohomai Institute of Technology in New Zealand. He received the degree of Doctor of Education from the University of Auckland and holds New Zealand teacher registration. He teaches a range of early childhood education courses at various levels. His current research interests include professional standards for teachers, teacher qualities, assessment for learning, curriculum and pedagogy, learning dispositions, and research methods. 